\title{
Effects of glutamine supplementation on oxidative stress-related gene expression and antioxidant properties in rats with streptozotocin-induced type 2 diabetes
}

\author{
Pei-Hsuan Tsai ${ }^{1}$, Jun-Jen Liu ${ }^{2}$, Chui-Li Yeh ${ }^{3}$, Wan-Chun Chiu ${ }^{1}$ and Sung-Ling Yeh ${ }^{1 *}$ \\ ${ }^{1}$ School of Nutrition and Health Sciences, Taipei Medical University, 250 Wu-Hsing Street, Taipei 110, Taiwan, ROC \\ ${ }^{2}$ School of Medical Laboratory Science and Biotechnology, Taipei Medical University, Taipei, Taiwan, ROC \\ ${ }^{3}$ Department of Food and Nutrition, Chinese Culture University, Taipei, Taiwan, ROC
}

(Submitted 9 March 2011 - Final revision received 10 June 2011 - Accepted 29 June 2011 - First published online 1 December 2011)

\begin{abstract}
There are close links among hyperglycaemia, oxidative stress and diabetic complications. Glutamine (GLN) is an amino acid with immunomodulatory properties. The present study investigated the effect of dietary GLN on oxidative stress-relative gene expressions and tissue oxidative damage in diabetes. There were one normal control (NC) and two diabetic groups in the present study. Diabetes was induced by an intraperitoneal injection of nicotinamide followed by streptozotocin (STZ). Rats in the NC group were fed a regular chow diet. In the two diabetic groups, one group (diabetes mellitus, DM) was fed a common semi-purified diet while the other group received a diet in which part of the casein was replaced by GLN (DM-GLN). GLN provided 25\% of total amino acid N. The experimental groups were fed the respective diets for 8 weeks, and then the rats were killed for further analysis. The results showed that blood thioredoxin-interacting protein (Txnip) mRNA expression in the diabetic groups was higher than that in the NC group. Compared with the DM group, the DM-GLN group had lower glutamine fructose-6-phosphate transaminase 1, a receptor of advanced glycation end products, and Txnip gene expressions in blood mononuclear cells. The total antioxidant capacity was lower and antioxidant enzyme activities were altered by the diabetic condition. GLN supplementation increased antioxidant capacity and normalised antioxidant enzyme activities. Also, the renal nitrotyrosine level and Txnip mRNA expression were lower when GLN was administered. These results suggest that dietary GLN supplementation decreases oxidative stress-related gene expression, increases the antioxidant potential and may consequently attenuate renal oxidative damage in rats with STZ-induced diabetes.
\end{abstract}

Key words: Glutamine: Diabetes: Thioredoxin-interacting protein: Glutamine fructose-6-phosphate transaminase 1: Nitrotyrosine

Diabetes mellitus (DM) is a metabolic disorder characterised by hyperglycaemia, disturbance of macronutrients, and the development of micro- and macrovascular complications. Increasing evidence from both experimental and clinical studies suggests that there are close links among hyperglycaemia, oxidative stress and diabetic complications ${ }^{(1,2)}$. There are four main hypotheses about how hyperglycaemia causes diabetic complications: (1) increased polyol pathway flux; (2) increased hexosamine pathway flux; (3) activation of protein kinase C (PKC) isoforms; (4) increased advanced glycation end-product (AGE) formation. These metabolic pathways are major contributors to reactive oxygen species (ROS) overproduction and high oxidative stress during hyperglycaemia ${ }^{(2-4)}$.
Glutamine (GLN) is the most abundant free amino acid in the circulation. Several studies have demonstrated that GLN has immunomodulating properties and suppresses inflammatory responses ${ }^{(5,6)}$. GLN is required during catabolic processes to manifest optimal tissue responses to catabolism, inflammation and infection. It is considered an essential amino acid during certain diseases ${ }^{(7,8)}$. A previous study has found that supplementing a high-fat diet with GLN attenuated hyperglycaemia in a diabetic rodent model ${ }^{(9)}$. A study by Greenfield et $a l .{ }^{(10)}$ demonstrated that GLN improved glycaemic control in type 2 diabetic patients. A recent study performed by our laboratory has also shown that supplemental dietary GLN decreased leucocyte adhesion molecule expression and oxidative stress in organs of mice with type 1 diabetes ${ }^{(11)}$.

Abbreviations: ABTS, 2,2'-azino-di-(3-ethylbenzthiazoline sulphonate); AGE, advanced glycation end product; AR, aldose reductase; BMC, blood mononuclear cell; DM, diabetes mellitus; GFAT, glutamine fructose-6-phosphate transaminase 1; GLN, glutamine; GPx, glutathione peroxidase; GSH, reduced glutathione; GSSG, oxidised glutathione; NC, normal control; PKC, protein kinase C; RAGE, receptor of AGE; ROS, reactive oxygen species; SOD, superoxide dismutase; STZ, streptozotocin; Txnip, thioredoxin-interacting protein.

* Corresponding author: Dr S.-L. Yeh, email sangling@tmu.edu.tw 
GLN is the precursor for the synthesis of glutathione (GSH). There is a significant correlation between GLN supply and intracellular GSH content ${ }^{(12)}$. There is increasing evidence that GLN supplementation enhances antioxidant capacity in various diseases $^{(13,14)}$. Because interruption of the production of superoxide would normalise the polyol pathway flux, AGE formation, PKC and NF- $\mathrm{KB}$ activation in diabetes ${ }^{(4)}$, we hypothesised that GLN supplementation reduces oxidative stress and thus decreases the associated pathway flux. Therefore, erythrocyte antioxidant enzyme activities and the total antioxidant capacity were measured. On the other hand, we analysed gene expressions of proteins in blood mononuclear cells (BMC) including aldose reductase (AR), glutamine fructose-6-phosphate transaminase 1 (GFAT) and PKC. AR is the first enzyme in the polyol pathway. It catalyses the NADPHdependent reduction of various carbonyl compounds. GFAT is the rate-limiting enzyme in the hexosamine pathway that converts glucose to glucosamine ${ }^{(3,4)}$. Abnormal activation of PKC was implicated in decreased glomerular production of $\mathrm{NO}$ induced by diabetes ${ }^{(15)}$. Also, the receptor of AGE (RAGE) and thioredoxin-interacting protein (Txnip) gene expressions were measured in the present study. The RAGE is a multi-ligand receptor of cell surface molecules. Binding of AGE to the RAGE activates a number of pathways implicated in chronic inflammation and the development of diabetic complications ${ }^{(16)}$. Thioredoxin is a highly conserved thiol reductase that interacts with the endogenous inhibitor Txnip $^{(17,18)}$. Hyperglycaemia inhibits thioredoxin's ROSscavenging function by inducing Txnip ${ }^{(19)}$. A previous report has found that Txnip expression significantly increases in diabetic animals, and may have implications in the development of end-stage organ damage in diabetics ${ }^{(17)}$. The present study was designed to investigate the effects of dietary GLN on oxidative stress-related gene expressions and its antioxidant properties. Because the kidneys are the major site of AGE clearance $^{(20)}$, and diabetic nephropathy is a complication that usually occurs in patients with poorly controlled disease, we evaluated oxidative damage to the kidneys in this streptozotocin (STZ)-induced diabetic model.

\section{Materials and methods \\ Animals}

Male Wistar rats, 6-weeks old, weighing 180-200g at the beginning of the experiment were used in the present study. All rats were housed in a temperature- and humiditycontrolled room and were allowed free access to a standard chow diet for 1 week before the study. Care of the laboratory animals was in full compliance with the Guide for the Care and Use of Laboratory Animals (National Research Council, 1996), and the protocols were approved by the Institutional Animal Care and Use Committee at Taipei Medical University.

\section{Study protocols}

Rats were assigned to one normal control (NC, $n$ 8) group and two diabetic groups ( $n$ 10, each). Diabetes was induced by an injection of $150 \mathrm{mg}$ nicotinamide/ $\mathrm{kg}$ (Sigma Chemical, St Louis, MO, USA) followed by STZ (Sigma) at a dose of $65 \mathrm{mg} / \mathrm{kg}$ after $15 \mathrm{~min}$ via an intraperitoneal route. The induction procedure was repeated $1 \mathrm{~d}$ later. Nicotinamide was dissolved in $0.9 \%$ saline, and STZ was dissolved immediately before use in sodium citrate $(0.05 \mathrm{~mol} / \mathrm{l} ; \mathrm{pH} 4.5)$. This is a well-established animal model to imitate type 2 diabetes ${ }^{(21)}$. Nicotinamide was used to protect pancreatic $\beta$-cells against STZ toxicity in order to build up a relative insulin-deficient state in rats that mimic type 2 diabetes ${ }^{(22)}$. Animals were allowed to eat laboratory chow ad libitum for 1 week. Rats with $12 \mathrm{~h}$ fasting blood glucose levels exceeding $2000 \mathrm{mg} / \mathrm{l}$ were considered diabetic. Rats in the NC group were fed a regular chow diet. In the two diabetic groups, one group (DM) was fed a common semi-purified diet, while the other group (DM-GLN) was provided an identical diet except that part of the casein was replaced by GLN, which provided $25 \%$ of total amino acid N. This amount of GLN was found to have beneficial effects on DM rodents ${ }^{(11)}$. The experimental diets were isonitrogenous and identical in energy and nutrient distributions (Table 1). After feeding the respective diets for 8 weeks, all rats were anaesthetised and killed by drawing arterial blood from the aorta of the abdomen. Blood samples were collected in tubes containing $\mathrm{K}_{2}$-EDTA (Sigma) and immediately centrifuged at $1500 \mathrm{~g}$ for $10 \mathrm{~min}$ to separate the plasma. Packed erythrocytes were washed three times with isotonic saline. The kidneys were rapidly excised. All samples were stored at $-80^{\circ} \mathrm{C}$ until further analysed.

\section{Measurement of plasma biochemical parameters}

Plasma glucose concentrations at the end of the study were determined by colorimetric methods after an enzymatic reaction with peroxidase (Randox, Antrim, Ireland). TAG, total cholesterol, HDL-cholesterol and LDL-cholesterol, creatinine and blood urea $\mathrm{N}$ were analysed by an autoanalyser (Hitachi 7170, Hitachi Limited, Tokyo, Japan). The procedures followed the manufacturers' instructions.

Table 1. Composition of the experimental diets $(\mathrm{g} / \mathrm{kg})$

\begin{tabular}{lcc}
\hline Components & DM & DM-GLN \\
\hline Soyabean oil & 100 & 100 \\
Casein & 200 & 150 \\
GLN & 0 & 41.7 \\
Salt mixture* & 35 & 35 \\
Vitamin mixture† & 10 & 10 \\
Methyl cellulose & 31 & 31 \\
Choline bitartrate & $2 \cdot 5$ & 2.5 \\
Met & 3 & 3 \\
Maize starch & 618.5 & 626.8 \\
\hline
\end{tabular}

$\mathrm{DM}$, diabetes without glutamine; DM-GLN, diabetes with glutamine; GLN, glutamine.

* The salt mixture contained the following $(\mathrm{mg} / \mathrm{g})$ : calcium phosphate dibasic, 500 ; $\mathrm{NaCl}, 74$; potassium sulphate, 52 ; potassium citrate monohydrate, 20 magnesium oxide, 24; manganese carbonate, 3.5; ferric citrate, 6; zinc carbonate 1.6; cupric carbonate, 0.3 ; potassium iodate, 0.01 ; sodium selenite, 0.01 ; chromium potassium sulphate, 0.55 .

† The vitamin mixture contained the following $(\mathrm{mg} / \mathrm{g})$ : thiamin hydrochloride, 0.6 ; riboflavin, 0.6 ; pyridoxine hydrochloride, 0.7 ; nicotinic acid, 3 ; calcium pantothenate, 1.6; D-biotin, 0.05; cyanocobalamin, 0.001; retinyl palmitate, 1.6; DL- $\alpha$-tocopherol acetate, 20; cholecalciferol, 0.25; menaquinone, 0.005. 


\section{Measurement of the plasma total antioxidant capacity}

The total antioxidant capacity was measured using an antioxidant assay kit (Cayman Chemical, Ann Arbor, MI, USA). The principle of the assay is the ability of aqueous and lipid antioxidants in the sample to inhibit the oxidation of $2,2^{\prime}$-azinodi-3-ethylbenzthiazoline sulphonate (ABTS) to $\mathrm{ABTS}^{+}$by metmyoglobin. The capacity of the antioxidants present in the sample to prevent ABTS oxidation was compared with that of standard Trolox, a water-soluble tocopherol analogue. All samples were diluted 1:30 with the assay buffer before being assayed. Trolox standards and reagent were prepared according to the manufacturer's instructions. Then, $10 \mu \mathrm{l}$ of Trolox standard and samples were loaded onto a ninety-sixwell plate. Also, $10 \mu \mathrm{l}$ of metmyoglobin and $150 \mu \mathrm{l}$ of chromogen were added to the wells. The reaction was initiated by adding $40 \mu \mathrm{H}_{2} \mathrm{O}_{2}$ as quickly as possible. The plate was covered and incubated for $5 \mathrm{~min}$ at room temperature and was monitored at an absorbance of $750 \mathrm{~nm}$ in a spectrophotometer. Samples and Trolox standards were assayed in duplicate. Results are presented as mm Trolox equivalents.

\section{Measurement of erythrocyte antioxidant enzyme} activities, and reduced and oxidised glutathione contents

To $100 \mu \mathrm{l}$ of packed erythrocytes, $300 \mu \mathrm{l}$ of cold redistilled water were added to lyse the cells. Then, the lysed erythrocytes were centrifuged at $15000 \boldsymbol{g}$ for $10 \mathrm{~min}$. The supernatants were used to analyse the antioxidant enzyme activities including those of catalase, glutathione peroxidase (GPx), glutathione reductase and superoxide dismutase (SOD; Randox). Total glutathione and oxidised glutathione (GSSG) were measured by a previously described enzymatic method ${ }^{(11)}$. The content of GSH was calculated as the difference between total glutathione and GSSG. To assay GSSG, we added $4 \mu \mathrm{l}$ of $10 \mathrm{~mm}$-1-methyl-2-vinylpyridinium (Sigma) to $70 \mu \mathrm{l}$ of packed erythrocytes (derivatised sample), mixed them and kept them at room temperature for $1 \mathrm{~h}$. After that, buffer $\mathrm{A}$ (200 $\mu \mathrm{m}-\mathrm{NADPH}, \quad 2$ units $/ \mathrm{ml}$ glutathionine reductase and $2 \mathrm{~mm}$-EDTA in $50 \mathrm{~mm}$-phosphate buffer) and buffer B (10 mm-5,5'-dithiobis-2-nitrobenzoic acid in $50 \mathrm{~mm}$-phosphate buffer) were immediately added to $10 \mu$ l of the derivatised sample. The change in the optical density at $5 \mathrm{~min}$ was measured with a spectrophotometer at $405 \mathrm{~nm}$. To determine total glutathione, buffers A and B were added to erythrocytes, and absorption was measured at $405 \mathrm{~nm}$. The glutathione content was calculated on the basis of a standard curve generated with a known concentration of glutathione. Enzyme activities, and GSH and GSSG contents are expressed per mg $\mathrm{Hb}$. $\mathrm{Hb}$ was determined by an autoanalyser (Hitachi).

\section{Total RNA extraction}

Blood samples were applied to a Ficoll-Hypaque gradient (Amersham Biosciences, Piscataway, NJ, USA), and BMC were separated by density gradient centrifugation with a density of $1.077 \mathrm{~g} / \mathrm{ml}$ for $30 \mathrm{~min}$ at $650 \mathrm{~g}$ and $4^{\circ} \mathrm{C}$. BMC were washed twice with sterilised PBS (Sigma) and resuspended in $0.5 \mathrm{ml}$ PBS. Total RNA from BMC was isolated using the Qiagen RNeasy Mini Kit (Qiagen, Crawley, Sussex, UK) according to the manufacturer's protocol. Total RNA of the kidneys was obtained from $50 \mathrm{mg}$ tissue by the guanidine isothiocyanate extraction method, using the Trizol Reagent (Invitrogen, Carlsbad, CA, USA). Chloroform was added and allowed to stand at room temperature for $10 \mathrm{~min}$. After centrifugation, the aqueous phase with RNA was transferred to a microtube. Cold isopropanol was added to the aqueous phase and precipitated by centrifugation. The RNA pellet was washed twice with $75 \%$ ethanol. The pellet was air-dried and dissolved in RNase-free water. The total RNA solution was stored at $-80^{\circ} \mathrm{C}$ for a subsequent assay. The concentration of RNA was determined and quantified by measuring the absorbance at 260 and $280 \mathrm{~nm}$ on a spectrophotometer.

\section{Real-time RT-PCR}

The primers of the housekeeping gene ( $\beta$-actin), AR, GFAT, PKC, RAGE and Txnip were purchased from Mission Biotech (Taipei, Taiwan). Primer sequences used for the quantitative RT-PCR assays are listed in Table 2. RNA was reversetranscribed using an RT system (Fermentas, Vilnius, Lithuania). Briefly, $12 \mu \mathrm{l}$ water containing $1 \mu \mathrm{g}$ RNA were mixed with $1 \mu \mathrm{l}$ oligo (dT) primer $(0.5 \mu \mathrm{g} / \mu \mathrm{l})$ and incubated for $5 \mathrm{~min}$ at $65^{\circ} \mathrm{C}$. To the mixture, $4 \mu \mathrm{l}$ of $5 \times$ RT buffer,

Table 2. Primer sequences used for inflammatory mediator quantitative real-time PCR assays

\begin{tabular}{|c|c|c|c|}
\hline Gene name & Accession no. & Primer sequence $\left(5^{\prime} \rightarrow 3^{\prime}\right)$ & Product size (bp) \\
\hline$\beta$-Actin & NM_031144.2 & $\begin{array}{l}\text { F: CACCAGTTCGCCATGGATGACGA } \\
\text { R: CCATCACACCCTGGTGCCTAGGGC }\end{array}$ & 145 \\
\hline$A R$ & X05884.1 & $\begin{array}{l}\text { F: GGCCAAGCCTGAGGACCCCT } \\
\text { R: ACCGGATCAGCACCTGGGCT }\end{array}$ & 95 \\
\hline GFAT & NM_001005879.1 & $\begin{array}{l}\text { F: CAGCGGTGTCGGCGGTTGA } \\
\text { R: TGACGGGTTGCCATACCAGCG }\end{array}$ & 68 \\
\hline$P K C-\beta$ & M19007.1 & $\begin{array}{l}\text { F: AGCCGGAGTGGATGGCTGGT } \\
\text { R: CTCGCTTTCTTCCGGCGGCA }\end{array}$ & 85 \\
\hline$R A G E$ & NM_053336.2 & $\begin{array}{l}\text { F: TGCCCAGCCTCCCCCTCAAA } \\
\text { R: GGGTGGCCACGCAGCTGTAG }\end{array}$ & 128 \\
\hline Txnip & BC088411.1 & $\begin{array}{l}\text { F: TGAGCTTCCTCAAGGGCCCCT } \\
\text { R: GTTGGCTGGCTGGGACGATCG }\end{array}$ & 99 \\
\hline
\end{tabular}

F, forward primer; R, reverse primer; AR, aldose reductase; GFAT, glutamine fructose-6-phosphate transaminase 1; PKC, protein kinase C; RAGE, receptor of advanced glycation end products; Txnip, thioredoxin-interacting protein. 
$2 \mu \mathrm{l}$ deoxyribonucleotide triphosphate $\operatorname{mix}(10 \mathrm{mmol} / \mathrm{l}), 1 \mu \mathrm{l}$ RNase inhibitor and $1 \mu \mathrm{l}$ MultiScribe-RT (200 U/ $\mu \mathrm{l})$ were added and incubated at $42^{\circ} \mathrm{C}$ for $60 \mathrm{~min}$, and then the reaction was terminated by heating to $70^{\circ} \mathrm{C}$ for $5 \mathrm{~min}$. Complementary DNA was used for the real-time PCR assay performed with an ABI 7300 sequence detection system (Applied Biosystems, Foster City, CA, USA) according to the supplied guidelines.

\section{Analysis of nitrotyrosine in kidney homogenates}

A $25 \%$ kidney homogenate was prepared in ice-cold lysis buffer (10\% SDS and $10 \mathrm{~mm}$-Tris base; $\mathrm{pH} 7.5)$ containing a protease inhibitor cocktail (Complete, Roche Diagnostics, Mannheim, Germany), using a homogeniser. The homogenates were centrifuged at $22000 \mathrm{~g}$ for $20 \mathrm{~min}$ to remove cell debris. Supernatants were used for the analysis of nitrotyrosine. Nitrotyrosine concentrations were measured using a commercial ELISA kit (Millipore, Bedford, MA, USA). Nitrobovine serum albumin (Sigma) was coated onto wells of microtitre strips, and nitrotyrosines were quantified using anti-nitrotyrosine antibodies. Competition was accomplished by adding $50 \mu \mathrm{l}$ organ supernatant samples and $50 \mu \mathrm{l}$ primary antibodies to the wells. Each competes with the coated nitrated proteins for antibody binding. The amount of antibody that binds to the coated nitro-bovine serum albumin is inversely proportional to the amount of nitrotyrosine present in the samples added to the well of the plate. The procedures followed the manufacturer's instructions.

\section{Statistical analysis}

Data are presented as mean values and standard deviations. All statistical analyses were performed using the SAS software package (SAS, Cary, NC, USA). Differences among different groups were determined by a one-way ANOVA followed by Duncan's post hoc test. $P<0.05$ was considered statistically significant.

\section{Results \\ Body weight and food intake}

There were no differences in the initial body weights among the three groups. The food intake (DM group 27.9 (SD $2.4) \mathrm{g} / \mathrm{d} v$. DM-GLN group $28.62(\mathrm{SD} 1.13) \mathrm{g} / \mathrm{d} ; P>0.05)$ or body weights (DM group 323.7 (SD 74.8) g $v$. DM-GLN group 332.5 (SD 90.1) g; $P>0.05$ ) after feeding the diets for 8 weeks did not differ between the two diabetic groups.

\section{Oxidative stress-related gene expressions by blood mononuclear cells}

Txnip mRNA expression was higher in the NC group. Compared with the DM group, the DM-GLN group had lower GFAT, RAGE and Txnip gene expressions. There were no differences in AR or PKC- $\beta$ mRNA expressions among the three groups (Fig. 1).

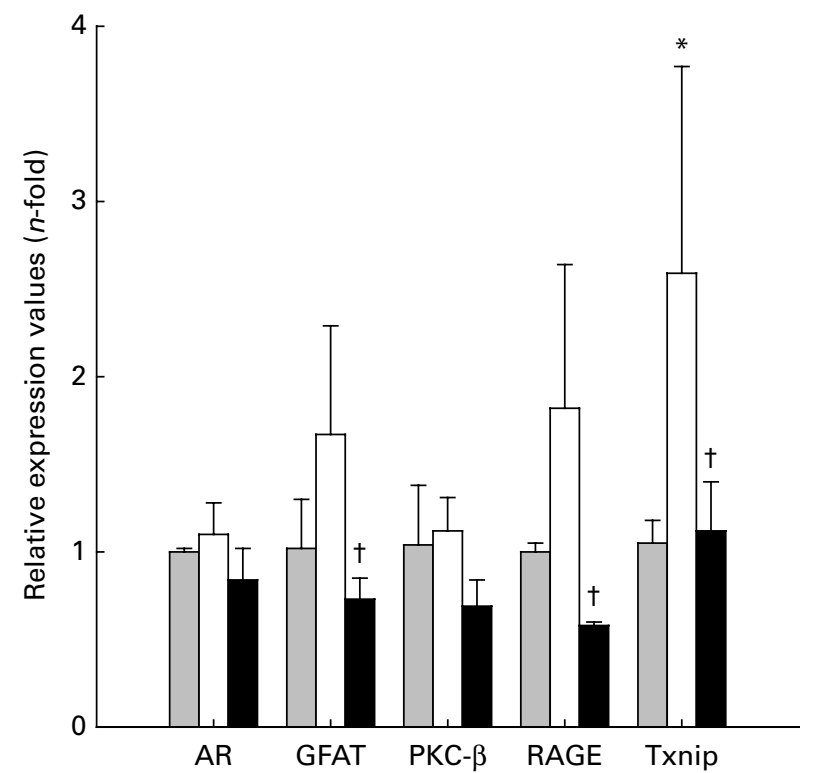

Fig. 1. Relative mRNA expressions of aldose reductase (AR), glutamine fructose-6-phosphate transaminase 1 (GFAT), protein kinase $C$ (PKC)- $\beta$, receptor of advanced glycation end products (RAGE) and thioredoxininteracting protein (Txnip) in blood mononuclear cells. Values are means of duplicate measurements, with standard deviations represented by vertical bars ( $n$ 4). Differences among the groups were analysed by one-way ANOVA followed by Duncan's post hoc test. * Mean values were significantly different from those of the normal control group (NC, $\square ; P<0.05)$. † Mean values were significantly different from those of the diabetes mellitus group (DM, $\square ; P<0 \cdot 05)$. DM-GLN ( $\square$ ), diabetes with glutamine.

\section{Plasma levels of biochemical parameters}

Plasma glucose, total cholesterol, HDL-cholesterol, LDLcholesterol, TAG and creatinine levels were significantly higher in the diabetic groups than in the NC group. There were no differences in glucose, total cholesterol, TAG, HDL-cholesterol, LDL-cholesterol, creatinine or blood urea N levels between the DM and DM-GLN groups (Table 3).

\section{Plasma total antioxidant capacity}

The total antioxidant capacity was significantly lower in the diabetic groups than in the NC group. The DM-GLN group had a higher total antioxidant capacity than the DM group (Table 4).

\section{Erythrocyte antioxidant enzyme activities, and reduced and oxidised glutathione levels}

GPX and SOD activities were significantly higher, while catalase activity was lower in the DM group than in the NC and DM-GLN groups. There were no differences in catalase, GPX or SOD activities between the NC and DM-GLN groups. The DM-GLN group had higher glutathione reductase activity than the NC and DM groups. There were no differences in GSH levels among the three groups; however, the GSSG level was significantly higher in the DM group than in the NC and DM-GLN groups (Table 4). 
Table 3. Plasma concentrations of glucose, TAG, total cholesterol (TC), HDL-cholesterol (HDL-C) and LDL-cholesterol (LDL-C), creatinine and blood urea nitrogen (BUN) in the various groups at the end of the experiment

(Mean values and standard deviations, $n 8$ for the normal control group (NC) and $n 10$ for each diabetic group)

\begin{tabular}{|c|c|c|c|c|c|c|}
\hline & \multicolumn{2}{|c|}{ NC } & \multicolumn{2}{|c|}{ DM } & \multicolumn{2}{|c|}{ DM-GLN } \\
\hline & Mean & SD & Mean & SD & Mean & SD \\
\hline Glucose (mg/l) & $1843^{a}$ & 137 & $4572^{b}$ & 769 & $4431^{b}$ & 629 \\
\hline TAG $(\mathrm{mg} / \mathrm{l})$ & $409^{a}$ & 71 & $806^{b}$ & 484 & $756^{\mathrm{b}}$ & 388 \\
\hline $\mathrm{TC}(\mathrm{mg} / \mathrm{l})$ & $391^{\mathrm{a}}$ & 49 & $605^{b}$ & 107 & $633^{b}$ & 174 \\
\hline HDL-C (mg/l) & $126^{a}$ & 10 & $273^{b}$ & 86 & $286^{\mathrm{b}}$ & 96 \\
\hline LDL-C (mg/l) & $164^{\mathrm{a}}$ & 31 & $222^{\mathrm{b}}$ & 53 & $254^{\mathrm{b}}$ & 57 \\
\hline Creatinine $(\mathrm{mg} / \mathrm{l})$ & $3.5^{a}$ & 0.2 & $3.8^{\mathrm{b}}$ & 0.4 & $3.9^{\mathrm{b}}$ & 0.2 \\
\hline BUN (mg/l) & 195 & 19 & 244 & 69 & 238 & 87 \\
\hline
\end{tabular}

DM, diabetes without glutamine; DM-GLN, diabetes with glutamine.

${ }^{\mathrm{a}, \mathrm{b}}$ Mean values within a row with unlike superscript letters were significantly different $(P<0.05$; one-way ANOVA with Duncan's post hoc test).

Txnip gene expression and nitrotyrosine levels in the kidneys

The DM group had higher Txnip mRNA expression than the NC and DM-GLN groups. The nitrotyrosine level was highest in the DM group. There were no differences in Txnip mRNA expressions or nitrotyrosine levels between the NC and DM-GLN groups (Table 5).

\section{Discussion}

Increased production of free radicals and/or an impaired antioxidant defence capability in diabetes indicate a central contribution of ROS to the pathological consequences of diabetes $^{(23)}$. Hyperglycaemia-induced overproduction of superoxide is the causal link between high glucose levels and diabetic complications. In the present study, we investigated the effect of GLN on key enzyme and protein expressions involved in major pathways responsible for hyperglycaemic damage.

The present results demonstrated that DM results in higher plasma glucose, lipid and creatinine levels, indicating that abnormal nutrient metabolism and renal function occurred. We also observed that the HDL-cholesterol level was higher in the DM groups than in the NC group. The rat is a species without endogenous cholesteryl ester or TAG transfer capacity, because its lipid transfer protein activity is relatively low ${ }^{(24)}$. Therefore, it is reasonable to have higher HDL-cholesterol when total plasma cholesterol is high in a diabetic condition. The findings of the present study did not show a decrease in glucose levels in diabetic rats after supplemental dietary GLN administration. The present results are inconsistent with previous reports which showed that supplementing GLN had positive effects on glucose metabolism by increasing insulin sensitivity which may lead to better glycaemic control $^{(9,10)}$. However, the present study is consistent with a previous study performed by our laboratory which also showed that dietary GLN did not affect plasma glucose ${ }^{(11)}$.

Hyperglycaemia results in increased enzymatic conversion of glucose to the polyalcohol sorbitol, with concomitant decreases in NADPH and $\mathrm{GSH}^{(4)}$. A previous study has found that AR inhibition prevented diabetic neuropathy in a 5-year animal study ${ }^{(25)}$. AGE originally arise from non-enzymatic reactions between extracellular proteins and glucose. Intracellular hyperglycaemia is the primary initiating event in the formation of AGE. AGE bind to the RAGE on endothelial cells, mesangial cells and macrophages, inducing receptor-mediated production of ROS, and activate the transcription factor NF-кB and subsequent gene expressions ${ }^{(4)}$. Blockade of the RAGE was shown to inhibit the development of diabetic nephropathy ${ }^{(26,27)}$. Hyperglycaemia may also indirectly activate PKC isoforms

Table 4. Plasma total antioxidant capacity and erythrocyte antioxidant enzyme activities, reduced (GSH) and oxidised glutathione (GSSG) at the end of the experiment

(Mean values and standard deviations, $n 8$ for the normal control group (NC) and $n 10$ for each diabetic group)

\begin{tabular}{|c|c|c|c|c|c|c|}
\hline & \multicolumn{2}{|c|}{ NC } & \multicolumn{2}{|c|}{ DM } & \multicolumn{2}{|c|}{ DM-GLN } \\
\hline & Mean & SD & Mean & SD & Mean & SD \\
\hline Trolox equivalents (mM) & $1 \cdot 84^{\mathrm{a}}$ & 0.33 & $0.98^{\mathrm{b}}$ & 0.36 & $1 \cdot 36^{\mathrm{c}}$ & 0.16 \\
\hline Catalase $(\mathrm{U} / \mathrm{g} \mathrm{Hb})$ & $12 \cdot 7^{\mathrm{a}}$ & 1.0 & $10 \cdot 7^{\mathrm{b}}$ & 1.6 & $12 \cdot 8^{\mathrm{a}}$ & 1.5 \\
\hline $\mathrm{GPx}(\mathrm{U} / \mathrm{g} \mathrm{Hb})$ & $606 \cdot 2^{\mathrm{a}}$ & 83.0 & $786 \cdot 2^{b}$ & $103 \cdot 3$ & $706 \cdot 1^{\mathrm{a}}$ & $119 \cdot 7$ \\
\hline GRd (U/g Hb) & $1 \cdot 1^{\mathrm{a}}$ & 0.2 & $1 \cdot 1^{\mathrm{a}}$ & 0.2 & $1 \cdot 3^{b}$ & 0.2 \\
\hline $\operatorname{SOD}(\mathrm{U} / \mathrm{g} \mathrm{Hb})$ & $6123^{a}$ & 1534 & $8669^{b}$ & 1220 & $6922^{\mathrm{a}}$ & 1871 \\
\hline $\mathrm{GSH}(\mu \mathrm{mol} / \mathrm{g} \mathrm{Hb})$ & 1.40 & 0.13 & 1.39 & 0.25 & 1.31 & 0.23 \\
\hline GSSG $(\mu \mathrm{mol} / \mathrm{g} \mathrm{Hb})$ & $0.10^{\mathrm{a}}$ & 0.02 & $2 \cdot 97^{\mathrm{b}}$ & 0.70 & $1 \cdot 19^{\mathrm{C}}$ & 0.27 \\
\hline
\end{tabular}

DM, diabetes without glutamine; DM-GLN, diabetes with glutamine; GPx, glutathione peroxidase; GRd, glutathione reductase; SOD, superoxide dismutase.

${ }^{a, b, c}$ Mean values within a row with unlike superscript letters were significantly different $(P<0.05$; one-way ANOVA with Duncan's post hoc test). 
Table 5. Kidney-relative thioredoxin-interacting protein (Txnip) mRNA expression and nitrotyrosine levels in kidney homogenates

(Mean values and standard deviations, $n 4$ for Txnip, $n 8$ for the normal control group (NC) and $n 10$ for each diabetic group for nitrotyrosine, representative of duplicate measurements)

through ligation of the RAGE and increased activity of the polyol pathway ${ }^{(28,29)}$. In early experimental diabetes, activation of PKC- $\beta$ was shown to mediate retinal and renal blood flow abnormalities ${ }^{(30)}$. Shunting of excess intracellular glucose into the hexosamine pathway plays an important role in hyperglycaemia-induced insulin resistance ${ }^{(31,32)}$. Also, it might cause several diabetic complications ${ }^{(33)}$. Previous studies ${ }^{(33,34)}$ showed that inhibition of GFAT blocks hyperglycaemia-induced increases in the transcription of inflammatory mediators. In the present study, we demonstrated that the DM-GLN group had lower GFAT and RAGE gene expressions, which might indicate that oxidative stress was lowered when GLN was administered. The favourable effect of GLN supplementation may have resulted from its antioxidant capacity in a diabetic condition. GLN was found to be rate limiting for GSH synthesis, and the availability of GLN is critical for generating GSH stores ${ }^{(35)}$. GSH represents the major source of cellular reducing equivalents, protecting cells against oxidative injury ${ }^{(36)}$. Although erythrocyte GSH levels did not increase in the present study, we did observe a decrease in GSSG levels in the DM-GLN group, which may have increased the GSH:GSSG ratio and antioxidant potential. The present results also showed that the total antioxidant capacity increased, whereas BMC Txnip gene expression decreased in the DM-GLN group. Txnip is an endogenous inhibitor of the ROS-scavenging protein thioredoxin ${ }^{(17,18)}$. The thioredoxin $\times$ Txnip interaction plays an important role in the cellular redox balance $^{(19)}$. Lower Txnip expression indicated that the ROSscavenging activity of thioredoxin had increased.

The findings of the present study revealed that the activity of catalase decreased, whereas those of GPx and SOD increased in the diabetic condition. SOD converts superoxide anion radicals produced in the body to $\mathrm{H}_{2} \mathrm{O}_{2}$. GPx metabolises $\mathrm{H}_{2} \mathrm{O}_{2}$ to water using GSH as a hydrogen donor. Since DM is a disease with high oxidative stress, the antioxidant enzyme activities increased in response to high levels of free radicals, such as GPx and SOD, as observed in the present study. The effects of diabetes on antioxidant enzyme activities are erratic and depend on the species of animal, the duration of diabetes and the tissue studied ${ }^{(37)}$. Also, there is not total agreement on the activities of these enzymes in a diabetic condition ${ }^{(37)}$. The reason why catalase activity was suppressed in the diabetic group is not clear. However, the present results are consistent with previous reports ${ }^{(38,39)}$. The finding that GLN supplementation normalised changes in the antioxidant enzyme system indicates that the imbalance between ROS generation and the antioxidant capacity was at least partly reversed by GLN administration.

Kidney nitrotyrosine levels were measured in the present study, because nitrotyrosine is considered a good marker of oxidative damage to proteins and of oxidative stress ${ }^{(40,41)}$. Nitration of the 3-position of tyrosine is the major product of a peroxynitrite attack on proteins. The findings of the present study showed that kidney nitrotyrosine levels were higher in the DM groups than in the NC group, indicating that the extent of NO oxidation increases with diabetes. The DM-GLN group had lower renal nitrotyrosine levels and Txnip gene expression, suggesting that oxidative damage to the kidneys was attenuated when GLN was administered in a diabetic condition.

In summary, the present study demonstrated that dietary GLN did not affect plasma glucose or lipid profiles. However, GFAT, RAGE, and Txnip mRNA expressions and renal nitrotyrosine levels were lower, whereas the total antioxidant capacity was higher and antioxidant enzyme activities were normalised in a diabetic condition when GLN was administered. These results suggest that dietary GLN supplementation decreases oxidative stress-related gene expressions, increases the antioxidant potential and may consequently attenuate renal oxidative damage in rats with STZ-induced type 2 diabetes.

\section{Acknowledgements}

This study was supported by a research grant (NSC97-2320B-038-038-MY3) from the National Science Council, Taiwan. P.-H. T. contributed to the concept of the study and performed most of the data analysis. J.-J. L. and C.-L. Y. performed part of the analysis. W.-C. C. helped interpret the data. S.-L. Y. designed the study and prepared the manuscript. All authors read and approved the final content of the manuscript. The authors declare that there are no conflicts of interest.

\section{References}

1. Wei W, Liu Q, Cai L, et al. (2009) Oxidative stress, diabetes, and diabetic complications. Hemoglobin 33, 370-377.

2. Giacco F \& Brownlee M (2010) Oxidative stress and diabetic complications. Circ Res 107, 1058-1070.

3. Johansen JS, Harris AK, Ergul A, et al. (2005) Oxidative stress and the use of antioxidants in diabetes: linking basic science to clinical practice. Cardiovasc Diabetol 4, 5 .

4. Brownlee M (2001) Biochemistry and molecular cell biology of diabetic complications. Nature 414, 813-820. 
5. Wischmeyer PE (2007) Glutamine: mode of action in critical illness. Crit Care Med 35, S541-S544.

6. Coeffier M \& Déchelotte P (2005) The role of glutamine in intensive care unit patients: mechanisms of action and clinical outcome. Nutr Rev 63, 65-69.

7. Parry-Billings M, Evans J, Newsholme EA, et al. (1990) Does glutamine contribute to immunosuppression after major burns? Lancet 336, 523-525.

8. Wilmore DW (2001) The effect of glutamine supplementation in patients following elective surgery and accidental injury. J Nutr 131, 2543S-2549S; discussion 2550S-2551S.

9. Opara EC, Petro A, Surwit RS, et al. (1996) L-Glutamine supplementation of a high fat diet reduces body weight and attenuates hyperglycemia and hyperinsulinemia in C57BL/6J mice. J Nutr 126, 273-279.

10. Greenfield JR, Farooqi IS, Blackwood A, et al. (2009) Oral glutamine increases circulating glucagon-like peptide 1, glucagon, and insulin concentrations in lean, obese, and type 2 diabetic subjects. Am J Clin Nutr 89, 106-113.

11. Tsai PH, Liu JJ, Chiu WC, et al. (2011) Effects of dietary glutamine on adhesion molecule expression and oxidative stress in mice with streptozotocin-induced type 1 diabetes. Clin Nutr 30, 124-129.

12. Roth E, Oehler R, Strasser E, et al. (2002) Regulative potential of glutamine - relation to glutathione metabolism. Nutrition 18, 217-221.

13. Alves WF, Aguiar EE, Soares Gdos S, et al. (2010) L-Alanylglutamine preoperative infusion in patients with critical limb ischemia subjected to distal revascularization reduces tissue damage and protects from oxidative stress. Ann Vasc Surg 24, 461-467.

14. Das S, Kar Mahapatra S, Roy S, et al. (2007) Oxidative stress in lymphocytes, neutrophils, and serum of oral cavity cancer patients: modulatory array of L-glutamine. Support Care Cancer 15, 1399-1405.

15. Craven PA, Studer RK \& DeRubertis FR (1994) Impaired nitric oxide-dependent cyclic guanosine monophosphate generation in glomeruli from diabetic rats. Evidence for protein kinase C-mediated suppression of the cholinergic response. J Clin Invest 93, 311-320.

16. Bierhaus A, Humpert PM, Arnold B, et al. (2005) Understanding RAGE, the receptor for advanced glycation end products. J Mol Med $\mathbf{8 3}, 876-886$.

17. Schulze PC, Yoshioka J, Lee RT, et al. (2004) Hyperglycemia promotes oxidative stress through inhibition of thioredoxin function by thioredoxin-interacting protein. $J$ Biol Chem 279, 30369-30374.

18. Turturro F, Friday E \& Welbourne T (2007) Hyperglycemia regulates thioredoxin-ROS activity through induction of thioredoxin-interacting protein (TXNIP) in metastatic breast cancer-derived cells MDA-MB-231. BMC Cancer 7, 96.

19. Nishiyama A, Matsui M, Nakamura H, et al. (1999) Identification of thioredoxin-binding protein-2/vitamin $\mathrm{D}(3)$ up-regulated protein 1 as a negative regulator of thioredoxin function and expression. $J$ Biol Chem 274, 21645-21650.

20. Miyata T, Ueda Y, Horie K, et al. (1998) Renal catabolism of advanced glycation end products: the fate of pentosidine. Kidney Int 53, 416-422.

21. Masiello P, Broca C, Gross R, et al. (1998) Experimental NIDDM: development of a new model in adult rats administered streptozotocin and nicotinamide. Diabetes 47, 224-229.

22. Masiello P, Novelli M, Fierabracci V, et al. (1990) Protection by 3 -aminobenzamide and nicotinamide against streptozotocin-induced beta-cell toxicity in vivo and in vitro. Res Commun Chem Pathol Pharmacol 69, 17-32.
23. Rolo AP \& Palmeira CM (2006) Diabetes and mitochondrial function: role of hyperglycemia and oxidative stress. Toxicol Appl Pharmacol 212, 167-178.

24. Groener JE, van Gent T \& van Tol A (1989) Effect of lipid transfer protein on plasma lipids, apolipoproteins and metabolism of high-density lipoprotein cholesteryl ester in the rat. Biochim Biophys Acta 1002, 93-100.

25. Engerman RL, Kern TS \& Larson ME (1994) Nerve conduction and aldose reductase inhibition during 5 years of diabetes or galactosaemia in dogs. Diabetologia 37, 141-144.

26. Yan SD, Schmidt AM, Zou YS, et al. (1994) Enhanced cellular oxidant stress by the interaction of advanced glycation end products with their receptors/binding proteins. $J$ Biol Chem 269, 9889-9897.

27. Lander HM, Tauras JM, Schmidt AM, et al. (1997) Activation of the receptor for advanced glycation end products triggers a p21(ras)-dependent mitogen-activated protein kinase pathway regulated by oxidant stress. J Biol Chem 272, 17810-17814.

28. Portilla D, Dai G, Proia AD, et al. (2000) Etomoxir-induced PPARalpha-modulated enzymes protect during acute renal failure. Am J Physiol Renal Physiol 278, F667-F675.

29. Keogh RJ, Dunlop ME \& Larkins RG (1997) Effect of inhibition of aldose reductase on glucose flux, diacylglycerol formation, protein kinase $\mathrm{C}$, and phospholipase A2 activation. Metabolism 46, 41-47.

30. Ishii H, Jirousek MR, Clermont A, et al. (1996) Amelioration of vascular dysfunctions in diabetic rats by an oral PKC beta inhibitor. Science 272, 728-731.

31. Marshall S, Bacote V \& Traxinger RR (1991) Discovery of a metabolic pathway mediating glucose-induced desensitization of the glucose transport system. Role of hexosamine biosynthesis in the induction of insulin resistance. $J$ Biol Chem 266, 4706-4712.

32. Hawkins M, Barzilai N, Rossetti L, et al. (1997) Role of the glucosamine pathway in fat-induced insulin resistance. J Clin Invest 99, 2173-2182.

33. Kolm-Litty V, Sauer U, Schleicher ED, et al. (1998) High glucose-induced transforming growth factor beta1 production is mediated by the hexosamine pathway in porcine glomerular mesangial cells. J Clin Invest 101, 160-169.

34. Du XL, Edelstein D, Ziyadeh F, et al. (2000) Hyperglycemiainduced mitochondrial superoxide overproduction activates the hexosamine pathway and induces plasminogen activator inhibitor-1 expression by increasing Sp1 glycosylation. Proc Natl Acad Sci U S A 97, 12222-12226.

35. Welbourne TC (1979) Ammonia production and glutamine incorporation into glutathione in the functioning rat kidney. Can J Biochem 57, 233-237.

36. Meister A \& Anderson ME (1983) Glutathione. Annu Rev Biochem 52, 711-760

37. Maritim AC, Sanders RA \& Watkins JBIII (2003) Diabetes, oxidative stress, and antioxidants: a review. J Biochem Mol Toxicol 17, 24-38.

38. Kedziora-Kornatowska KZ, Luciak M, Pawlak W, et al. (1998) Effect of aminoguanidine on erythrocyte lipid peroxidation and activities of antioxidant enzymes in experimental diabetes. Clin Chem Lab Med 36, 771-775.

39. Sailaja Devi MM, Suresh Y \& Das UN (2000) Preservation of the antioxidant status in chemically-induced diabetes mellitus by melatonin. J Pineal Res 29, 108-115.

40. Piconi L, Quagliaro L \& Ceriello A (2003) Oxidative stress in diabetes. Clin Chem Lab Med 41, 1144-1149.

41. Beckman JS \& Koppenol WH (1996) Nitric oxide, superoxide, and peroxynitrite: the good, the bad, and ugly. Am J Physiol 271, C1424-C1437. 